Vol. 9, n² | 2005

Varia

\title{
Mario Sbriccoli (1941-2005)
}

\section{Luigi Lacchè}

\section{OpenEdition}

Journals

Édition électronique

URL : https://journals.openedition.org/chs/346

DOI : $10.4000 /$ chs.346

ISSN : 1663-4837

\section{Éditeur}

Librairie Droz

\section{Édition imprimée}

Date de publication : 1 décembre 2005

Pagination : 155-156

ISBN : 978-2-600-01054-2

ISSN : 1422-0857

Référence électronique

Luigi Lacchè, " Mario Sbriccoli (1941-2005) », Crime, Histoire \& Sociétés / Crime, History \& Societies [En ligne], Vol. 9, n² | 2005, mis en ligne le 11 février 2009, consulté le 23 mars 2022. URL : http:// journals.openedition.org/chs/346 ; DOI : https://doi.org/10.4000/chs.346

Ce document a été généré automatiquement le 23 mars 2022

(C) Droz 


\title{
Mario Sbriccoli (1941-2005)
}

\author{
Luigi Lacchè
}

1 La mort subite de Mario Sbriccoli - le $1^{\text {er }}$ août dernier - laisse un héritage scientifique très important et un vide qui sera bien difficile à combler. Par plusieurs aspects, en effet, son parcours intellectuel possède des caractères particulièrement originaux. Né en 1941 à Camerino (Mc), Mario Sbriccoli, fils d'un directeur de banque, étudie dès le début des années 1960, à la Faculté de Droit de Macerata, la ville universitaire où il vécut depuis son enfance. Élève du professeur Paolo Grossi, un des Maestri de l'histoire juridique au plan international, Mario Sbriccoli a rapidement débuté son activité de recherche et d'enseignement. "Professeur ordinaire» depuis 1975, il a enseigné l'histoire du droit à la Faculté de Droit de Macerata jusqu'en 2005. Très apprécié des étudiants et universellement considéré par ses collègues, il a été à deux reprises, de 1979 à 1985, doyen de la Faculté et depuis l'an 2000 il était devenu le doyen de l'Université de Macerata. Il y avait fondé l'« Istituto di studi storici» dont il a fait une école reconnue au niveau national en raison de son excellence.

2 Mario Sbriccoli s'est fait connaître par son premier livre, L'interpretazione dello Statuto. Contributo allo studio della funzione dei giuristi nell'età comunale (Milan, 1969), devenu bientôt un «classique » dont la lecture est indispensable pour l'étude de la tradition juridique au moyen-âge. Au début des années 1970, s'affirme son intérêt pour l'histoire du droit pénal. Cet intérêt deviendra sa grande vocation scientifique. Il va ainsi profondément marquer l'étude du délit politique à l'époque moderne mais aussi aux dix-neuvième et vingtième siècles par son ouvrage Crimen laesae maiestatis (Milan, 1974). Depuis lors - et jusqu'à sa mort - Mario Sbriccoli devient un point de repère international pour tous ceux qui s'intéressent au pénal, à l'histoire de la criminalité et de la justice. En vérité, le nom de Sbriccoli illustre l'histoire du droit de punir, tant au niveau national qu'international, tellement il s'y identifie. Qu'il s'agisse de l'émergence du pénal public dans les cités italiennes des $\mathrm{XIII}^{\mathrm{e}}$ et XIV ${ }^{\mathrm{e}}$ siècles, de la formation d'un pénal hégémonique à l'âge moderne, de l'iconographie de la justice et de ses allégories, des transformations du droit pénal entre le XIX et le XX ${ }^{e}$ siècle jusqu'au fascisme et la naissance de la République italienne, l'intelligence, Mario Sbriccoli en impose par l'ampleur des horizons de recherche, l'originalité, la subtilité, l'érudition. 
3 Mario Sbriccoli a été un savant très attentif à dialoguer avec les «autres »: dans ses nombreux écrits méthodologiques et dans la pratique historiographique - même s'il a toujours affirmé la nécessité de valoriser le 'juridique' - il a sans cesse recherché le rapprochement et la communication, indispensables à ses yeux, avec les langages et les méthodes des autres sciences sociales, affinant une approche très originale. Voyageur infatigable, il a participé pendant des années aux événements scientifiques les plus importants. Sur le plan international, rappelons son activité constante, notamment comme acteur de leur fondation et membre actif de leurs organes de direction, notamment de l'International Association for the History of Crime and Criminal Justice et du Groupe Européen de Recherche sur les Normativités (CNRS). Rédacteur de la revue Déviance \& Société, Mario Sbriccoli a été cofondateur de Crime, Histoire \& Sociétés/Crime, History \& Societies. L'article sur l'iconographie de la justice qui, par un concours de circonstances, est paru au moment-même de sa disparition (CHS, 2005/1) illustre magnifiquement ses qualités.

4 La mort nous a enlevé le Maestro, l'ami très cher, l'homme généreux que nous tous avons connu.

\section{AUTEUR}

\section{LUIGI LACCHÈ}

(Università di Macerata) 